Erratum

\title{
Erratum to "Generalized Peritonitis Secondary to Spontaneous Perforation of Pyometra in a 63-Year-Old Patient"
}

\author{
Ahmed Abu-Zaid, ${ }^{1}$ Osama AlOmar, ${ }^{2}$ Ahmed Nazer, ${ }^{2}$ Ayman Azzam, ${ }^{3}$ \\ Zainab Abudan, ${ }^{1}$ and Ismail A. Al-Badawi ${ }^{2}$ \\ ${ }^{1}$ College of Medicine, Alfaisal University, P.O. Box 50927, Riyadh 11533, Saudi Arabia \\ ${ }^{2}$ Department of Obstetrics and Gynecology, King Faisal Specialist Hospital and Research Center (KFSH↔RC), P.O. Box 3354, Riyadh \\ 11211, Saudi Arabia \\ ${ }^{3}$ Department of General Surgery, Faculty of Medicine, Alexandria University, Alexandria 21526, Egypt \\ Correspondence should be addressed to Ahmed Abu-Zaid; aabuzaid@alfaisal.edu \\ Received 3 October 2013; Accepted 20 October 2013; Published 9 January 2014 \\ Copyright (C) 2014 Ahmed Abu-Zaid et al. This is an open access article distributed under the Creative Commons Attribution \\ License, which permits unrestricted use, distribution, and reproduction in any medium, provided the original work is properly \\ cited.
}

The name of the senior author (Ismail Al-Badawi) was spelled incorrectly and is corrected here as Ismail A. Al-Badawi. 


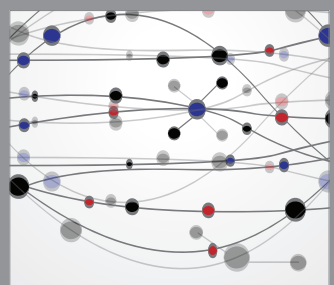

The Scientific World Journal
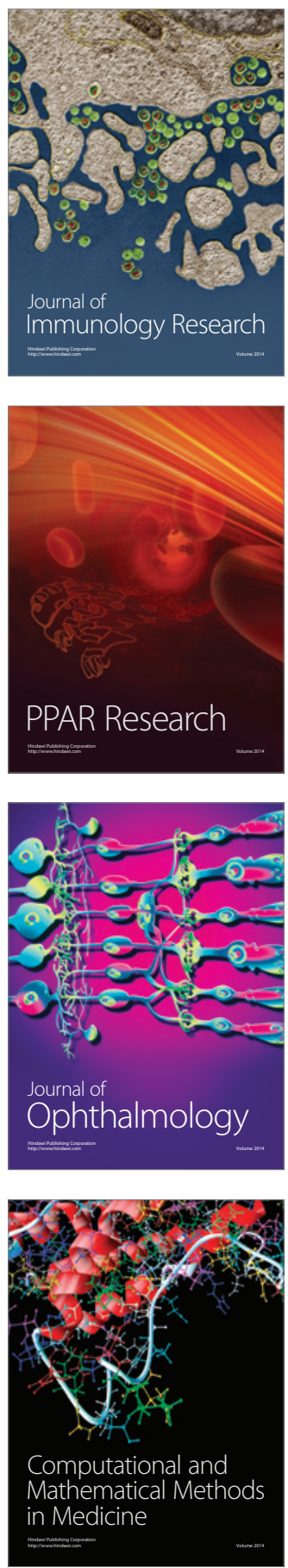

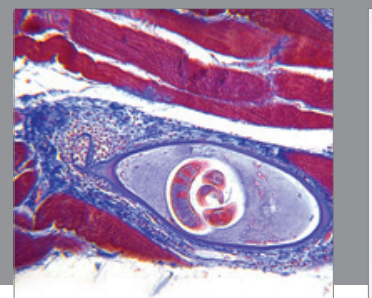

Gastroenterology

Research and Practice
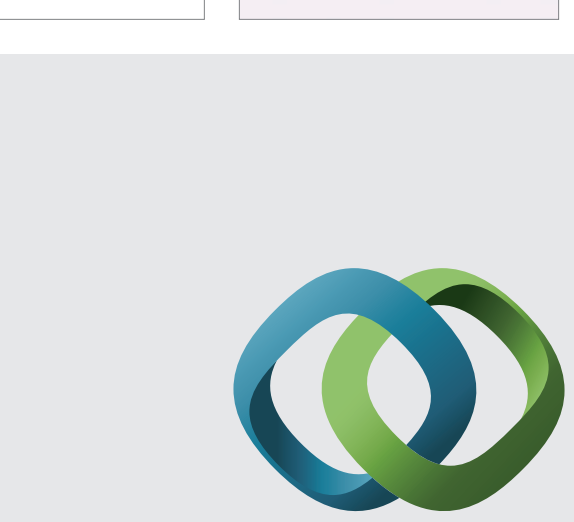

\section{Hindawi}

Submit your manuscripts at

http://www.hindawi.com
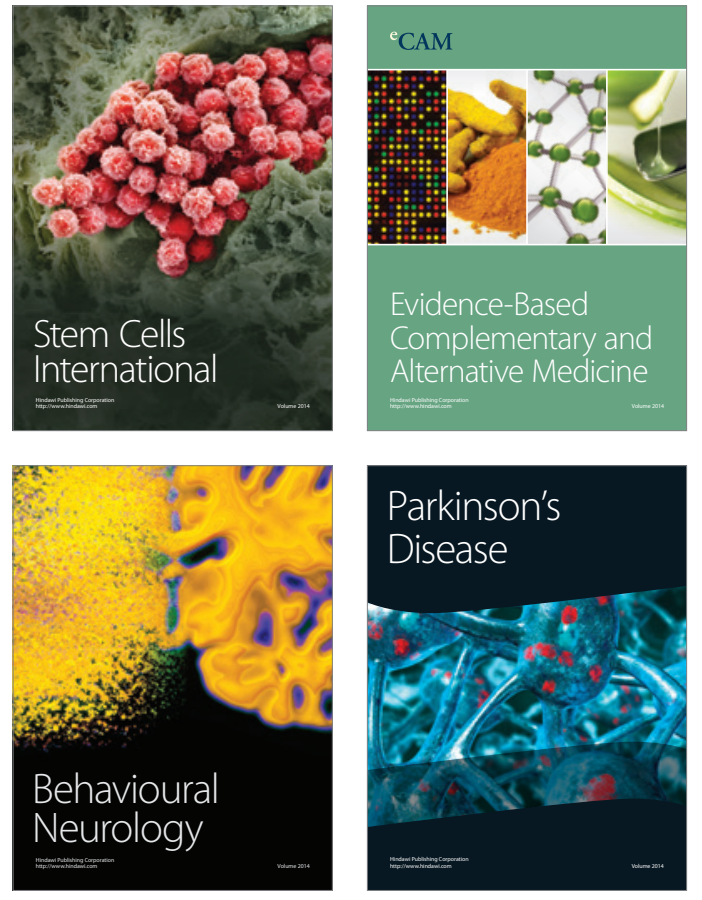
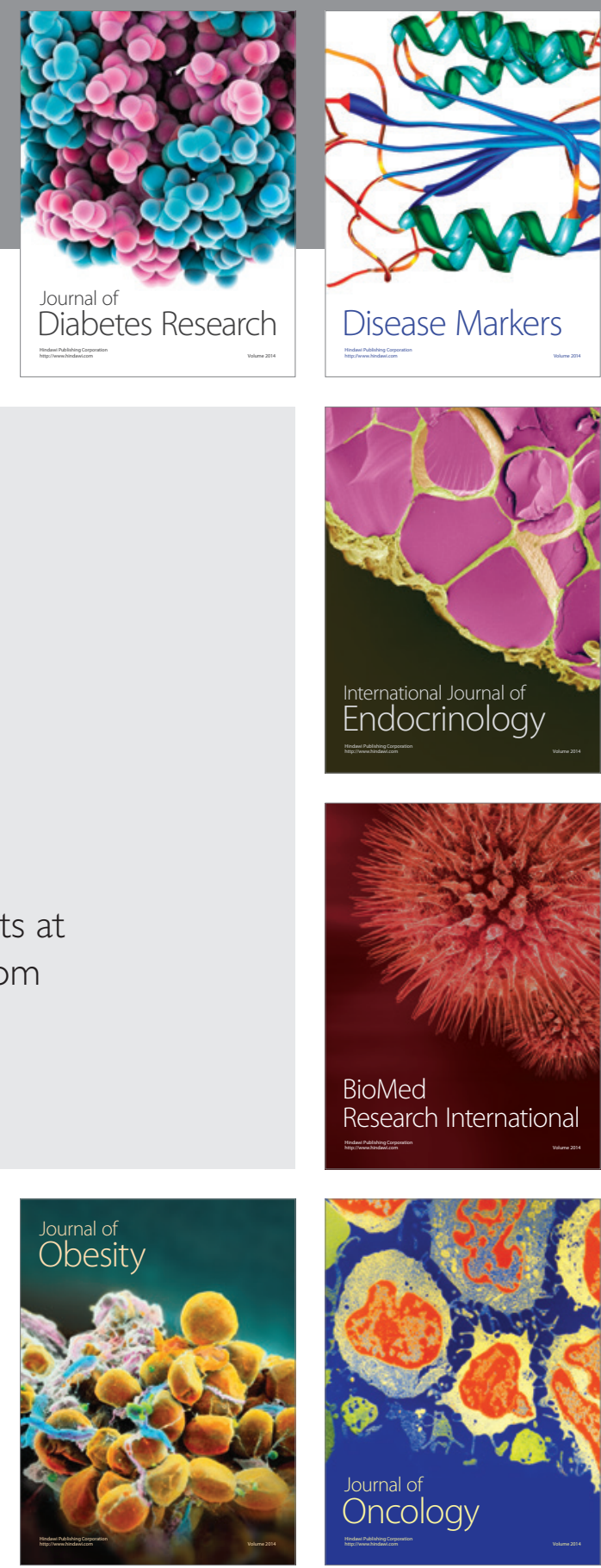

Disease Markers
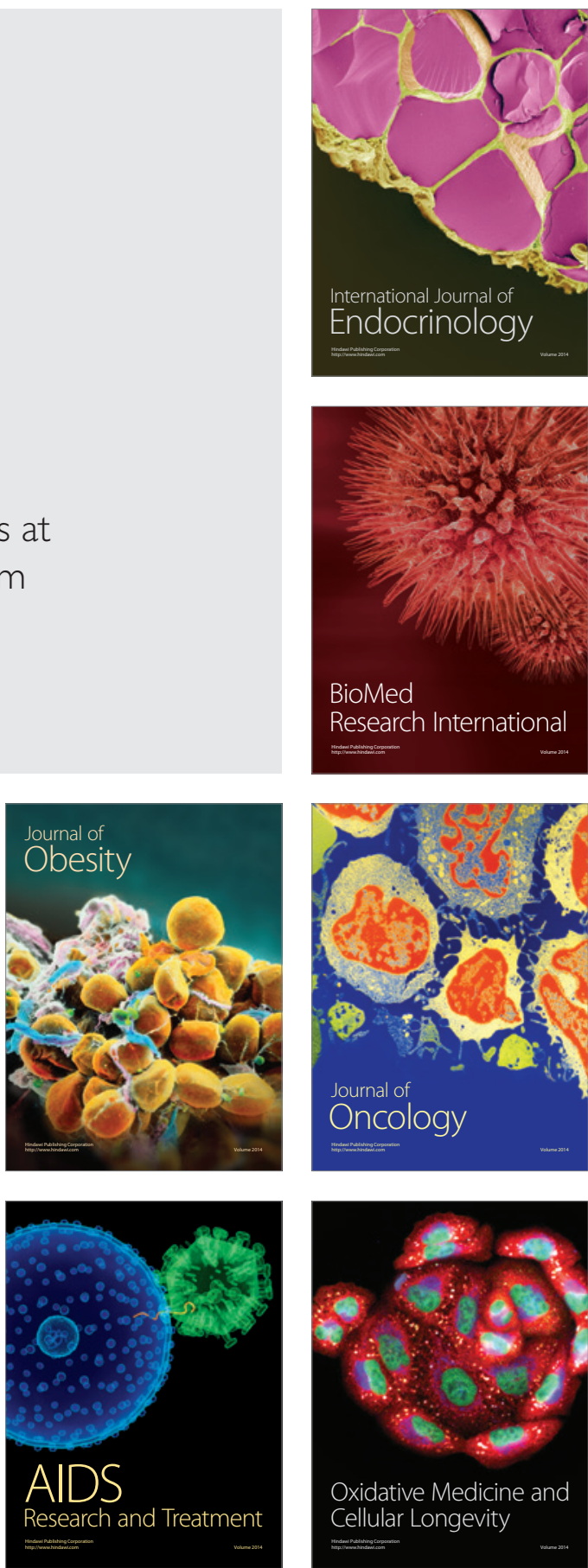